\title{
THEORETICAL STUDY OF THE ISOMERIZATION OF MALEIC ACID INTO FUMARIC ACID
}

\author{
RICARDO UGARTE*, CARLOS BUSTOS, IGNACIO MORENO-VILLOSLADA \\ Instituto de Química. Facultad de Ciencias. Universidad Austral de Chile. Casilla 567, Valdivia-Chile. \\ (Received: April 24, 2010 - Accepted: May 9, 2011)
}

\begin{abstract}
The isomerization reaction of 2-butenedioic acid in gas phase has been studied using Hartree-Fock (HF), Møller-Plesset to 2 ${ }^{\text {nd }}$ order (MP2) and BLYP, B3LYP Density Functional Theory (DFT) levels of approximation. Potential energy surfaces (PES) of the singlet and triplet states of the molecule are constructed in order to corroborate the hypothesis that the reaction proceeds by a non-adiabatic path. A total of ten stationary points (eight singlet and two triplet) were characterized as energy minima or saddle points. Thermochemical analysis of the triplet conformers and singlet most stable structures yields a value of the $\Delta \mathrm{H}^{\circ}$ of activation for isomerization that is in good agreement with the expected results.
\end{abstract}

Keywords: Potential energy surface; Isomerization Maleic acid; DFT calculations.

\section{INTRODUCTION}

As is well known, substituted ethylenes exhibit cis-trans isomerism. For instance maleic acid transforms into fumaric acid at high temperatures (melting point); this transformation is often accompanied by partial descomposition. The isomerization also occurs by heating an aqueous solution of maleic acid in a sealed tube above $130^{\circ} \mathrm{C}$, by catalyzing with various acids and salts at $\approx 100^{\circ}$ $\mathrm{C}$ and as a result of bromine atoms. ${ }^{1-9}$ The first investigation on the temperature dependence of the isomerization kinetics for the maleic acid in the liquid state was performed by Hojendal. ${ }^{10} \mathrm{He}$ found an activation energy of $15.8 \mathrm{kcal} \mathrm{mol}^{-1}$.

Experimental results have supported the classification of cis-trans isomerizations in two groups which involve rotation about ethylenic double bond. They are both first order reactions. The first group have an Arrhenius rate constant of $\approx 10^{11} \exp (-45,000 / \mathrm{RT})$, with a high frequency factor. ${ }^{11}$ Phenylsubstituted ethylenes (stilbene, methyl cinnamate) isomerizations belong to this group, and it is considered that the molecules remain in a singlet state throughout the isomerization process. The second group, to which maleic acid isomerization belongs, have an Arrhenius rate constant of $\approx 10^{4} \exp (-25,000$ / $\mathrm{RT})$. In this case, it is considered that the isomerization mechanism involves changing from singlet state to triplet state, and then to singlet state; the low frequency factor is a result of the difficulty associated with these changes. In chemical kinetics the word "adiabatic" has come to refer to a process in which there is no change of quantum state. According to the so-called "adiabatic hypothesis", it is supposed that the electrons remain in equilibrium with the particular nuclear configuration which occurs at a given moment, due to the large speed of the electronic motions relative to those of the nuclei. There are no electronic transitions (e.g. multiplicity changes) during the course of the reaction and the whole process takes place on a single potential energy surface. In consequence, the maleic acid isomerization will be referred as a non-adiabatic reaction (singlet $\rightarrow$ triplet $\rightarrow$ singlet).

The aim of this paper is to justify the assumption that the interconversion proceeds by a non-adiabatic path. That is, we will show that the possible triplet structures of the transition state for the maleic acid $\rightarrow$ fumaric acid interconversion have a lower energy than the corresponding singlet structures. In order to find the most stable conformations of maleic and fumaric acids, the potential energy surfaces (PES) at HF/6-31G(d) level for both electronic states, singlet and triplet, are constructed. The most suitable conformers of the aforementioned PES are chosen and geometry optimizations of these structures at different levels of theory are performed. Thermodynamic functions of the resulting isomerization reaction in gas phase are calculated and the value of the energy for the intramolecular hydrogen bond in maleic acid is estimated. As a consequence of the previous study, the potential energy surfaces at BLYP/STO$6 \mathrm{G}$ level for both singlet and triplet states are calculated; these potential energy surfaces are superimposed and stationary points and low energy reaction paths are localized. Our theoretical results are compared with experimental results.

\section{Methods}

All $a b$ initio Hartree-Fock (HF), Møller-Plesset (MP2) and Density Functional Theory (DFT) calculations in vacuo were carried out with the Gaussian 03 program package ${ }^{12}$ running on a Dell PowerEdge R805 server.

Potential energy surfaces (PES) are constructed by varying the dihedral angles $\Phi_{1}$ and $\Phi_{2}$ (see Figure 1). These angles determine the possible conformations of the molecule. Bear in mind that the dihedral angle $\Phi_{1}$ of the bonded atoms $\mathrm{C}_{5}-\mathrm{C}_{1}-\mathrm{C}_{3}-\mathrm{C}_{6}$ is the angle between the planes $\mathrm{C}_{5}-\mathrm{C}_{1}-\mathrm{C}_{3}$ and $\mathrm{C}_{1}-\mathrm{C}_{3}-\mathrm{C}_{6}$. Viewed from the direction of $\mathrm{C}_{5}, \Phi_{1}$ is positive for clockwise and negative for anticlockwise rotations. The value $\Phi_{1}=0^{\circ}$ corresponds to the planar-cis arrangement of the bonds $\mathrm{C}_{5}-\mathrm{C}_{1}$ and $\mathrm{C}_{3}-\mathrm{C}_{6}$ (maleic acid), while the value $\Phi_{1}=180^{\circ}$ corresponds to the planar-trans arrangement (fumaric acid). The PES of the 2-butenedioic acid were calculated using a $19 \times 19$ grid generated by rotating through $\Phi_{1}$ and $\Phi_{2}$ in $20^{\circ}$ increments from -180 to $+180^{\circ}$. At each point a complete geometry optimization was performed with $\Phi_{1}$ and $\Phi_{2}$ frozen at their respective grid values. In order to obtain local minima, unconstrained geometry optimizations (full optimizations) were performed with a set of initial conformations chosen to lie close to the minima found on the PES. Conformational energy map (contour diagram) were drawn in order to facilitate the analysis of the data and to suggest possible reaction paths.

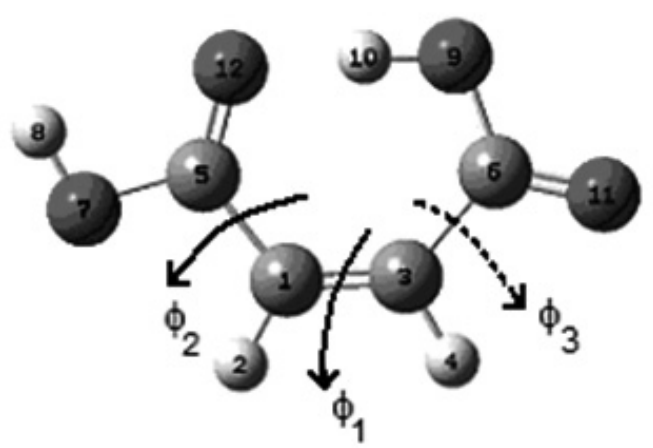

Figure 1. Dihedral angles $\Phi_{1}$ and $\Phi_{2}$ and definition of atom labels of 2-butenedioic acid. In the conformation shown here $\Phi_{1}=0^{\circ}$ (maleic acid); $\Phi_{2}=$ $180^{\circ} ; \Phi_{3}=0^{\circ} . \Phi_{1}\left(\mathrm{C}_{5}-\mathrm{C}_{1}-\mathrm{C}_{3}-\mathrm{C}_{6}\right) ; \Phi_{2}\left(\mathrm{O}_{7}-\mathrm{C}_{5}-\mathrm{C}_{1}-\mathrm{C}_{3}\right) ; \Phi_{3}\left(\mathrm{C}_{1}-\mathrm{C}_{3}-\mathrm{C}_{6}-\mathrm{O}_{9}\right)$. 
In order to construct the preliminary potential energy surfaces, the Restricted Hartree-Fock (RHF) and Unrestricted Hartree-Fock (UHF) ab initio procedure with the standard $6-31 \mathrm{G}(\mathrm{d})$ basis set was employed. These calculations are relatively inexpensive in computational terms and yield reasonable structural data. Vibrational frequency calculations were carried out to confirm the nature of all stationary points: local minima had no negative (imaginary) frequency, saddle points had exactly one negative frequency and second-order saddle points had exactly two negative frequencies. With the purpose of having theoretical results of the isomerization energies as close as possible to the experimental ones, the most relevant HF/6-31G(d) optimized structures obtained from the singlet and triplet PES were used as the first estimate or starting point for calculations at different levels of theory: HF/6-31G(d,p), MP2/6-31G(d,p), DFT-B3LYP/6-31G(d,p), ${ }^{13}$ DFT-BLYP/6$31 \mathrm{G}(\mathrm{d}, \mathrm{p})$ and DFT-BLYP/STO-6G.

Following the indications provided by the preliminary calculations (trial and error), the BLYP hybrid functional ${ }^{14,15}$ with the minimal STO6G basis set produces results which are closer to the experimental values. In DFT calculations, BLYP can be invoked in Gaussian 03 using the Iop(3/76), Iop(3/77), and Iop(3/78) statements. In this work, we utilized a user-defined model that contains the following keywords: \# blyp/sto-6g $\operatorname{iop}(3 / 76=1000005800)$ iop $(3 / 77=0500004200)$ iop $(3 / 78=0420004000)$. Thus, we have considered $58 \%$ Hartree-Fock and $42 \%$ DFT exchange energies.

In order to obtain standard termochemical data $(298.15 \mathrm{~K}, 1 \mathrm{~atm})$, the optimized structures at the different levels of theory were submitted to frequency calculations. All thermodynamic quantities are evaluated under ideal gas and rigid rotor-harmonic oscillator approximation. The dominant error in the above approximation may be the failure of the harmonic approximation for low-frequency vibrations which are rotational in nature. In our system, there are some low-vibrational frequencies; in this case, it is often more appropriate to compute the thermal component associated with these modes using a hindered rotor approximation. In this work, we request to the Gaussian 03 program the identification of internal rotation modes during the harmonic vibrational analysis, in order to correct the thermodynamic functions. However, when the calculation failed under this approximation, no hindered rotor approximation was used. Associated errors are not significant and therefore do not invalidate the analysis of results. The rotational and the translational contributions to the thermal quantities are taken from the classical expressions. The vibrational contributions are evaluated with the unscaled normal mode frequencies. The relative energies account for the zero-point-vibrational energy correction.

As a consequence of the analysis of the obtained results, the potential energy surfaces at BLYP/STO-6G level for both singlet and triplet states were constructed. In order to obtain information about possible reaction paths through a non-adiabatic process, we superimpose both PES and obtain another combined PES containing the lowest value of the energy for each pair of dihedral angles.

\section{RESULTS AND DISCUSSION}

The HF/6-31G(d) conformational energy map (contour diagram) of 2-butenedioic acid is shown in Figure 2 for both the singlet and triplet electronic states. The molecular structures close to the value $\Phi_{1}=0^{\circ}$ represent the maleic acid, while those close to the value $\Phi_{1}=180^{\circ}$ represent the fumaric acid. The global minimum at singlet potential energy surface (S-PES) are located in $\left[\Phi_{1}\right.$, $\left.\Phi_{2}\right]=\left[180^{\circ}, 180^{\circ}\right]$; at triplet PES (T-PES) in $\left[\Phi_{1}, \Phi_{2}\right]=\left[ \pm 90^{\circ}, 180^{\circ}\right]$. Starting from an analysis of these contour diagrams, full optimizations were performed with a set of initial conformations chosen to lie close to the minima found on the PES. Thus, different local minima (stable conformations) were found.
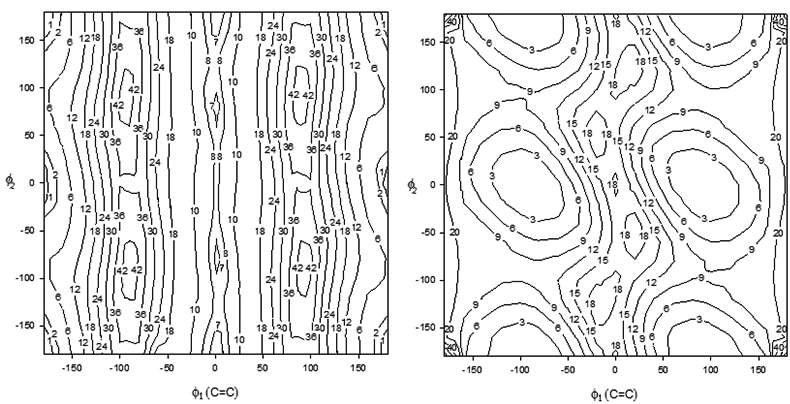

Figure 2. Conformational energy map of 2-butenedioic acid. Singlet: [RHF/6-31G(d)] (left) and Triplet: [UHF/6-31G(d)] (right). $\Delta \mathrm{E}_{\mathrm{HF}}$ in $\mathrm{kcal}^{\mathrm{mol}}{ }^{-1}$ with respect to the global minimum of each PES.
From the standard enthalpy change of formation $\left(\Delta_{\mathrm{t}} \mathrm{H}^{\circ}\right)$ in gaseous phase of the acids ${ }^{16}$ it can be inferred that the enthalpy difference for the isomerization reaction cis $\rightarrow$ trans is $+0.86 \mathrm{kcal} \mathrm{mol}^{-1}$. This energy value indirectly corroborates the stabilizing effect of the intramolecular hydrogen bonding in maleic acid (see Figure 1). In solid phase, the experimental isomerization enthalpy is approximately of $-4.9 \mathrm{kcal} \mathrm{mol}^{-1}$, revealing that the preferred form corresponds to the fumaric acid. The above, is a consequence of the larger number of intermolecular hydrogen bonds involved in the trans isomer with respect to the cis isomer in solid phase.

In order to compare with experimental results, we decided to submit some of the previously obtained $\mathrm{HF} / 6-31 \mathrm{G}(\mathrm{d})$ conformers, namely $\mathrm{S}_{\mathrm{I}}, \mathrm{S}_{\mathrm{IV}}, \mathrm{T}_{\mathrm{II}}$ and $\mathrm{S}_{\mathrm{V}}$ (see Figure 3), to geometry optimizations at different levels of theory. The justification of the choice of these structures is based on the following: the enthalpy difference of the $S_{I} \rightarrow S_{V}$ process can be compared to the previously mentioned experimental gas phase value; $T_{I}$ conformer represent a minimum on the T-PES, and could be identified as hypothetical "activated complex" and finally, the energy difference between $\mathrm{S}_{\mathrm{I}}$ and $\mathrm{S}_{\mathrm{IV}}$ gives us an estimate of the intramolecular hydrogen bond energy. According to this, a structural and thermochemical analysis at $298.15 \mathrm{~K}$ and $1 \mathrm{~atm}$ was performed.
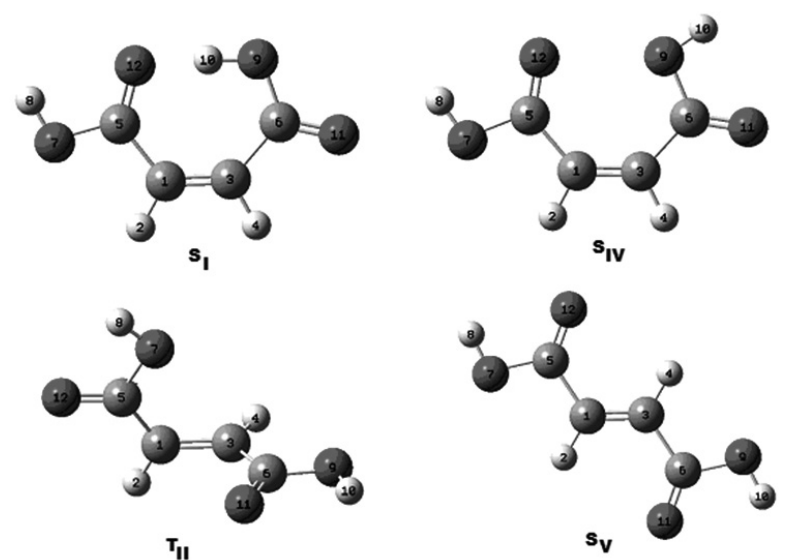

Figure 3. Relevant BLYP/STO-6G conformers of the 2-butenedioic acid. S: Singlet; T: Triplet.

Inspection of Table 1 reveals that the calculated BLYP/STO-6G enthalpy change $\left(+0.80 \mathrm{kcal} \mathrm{mol}^{-1}\right)$ for the cis $\rightarrow$ trans isomerization reaction $\left(\mathrm{S}_{\mathrm{I}} \rightarrow\right.$ $\mathrm{S}_{\mathrm{v}}$ ) approximates to the experimental value in gas phase. All methods of calculation, except the BLYP/STO-6G, overestimate the energy gap between $\mathrm{S}_{\mathrm{I}}$ and $\mathrm{S}_{\mathrm{y}}$, and give negative enthalpy differences, which is qualitatively in disagreement with experiments. Apparently, and without regard of other aspects, the intramolecular hydrogen bonding are badly reproduced by these calculations, in particular by Hartree-Fock method.

Table 1. Relative enthalpy in $\mathrm{kcal} \mathrm{mol}^{-1}$ of relevant conformers obtained by several methods reported with respect to the $\mathrm{S}_{\mathrm{V}}$ conformer (fumaric acid).

\begin{tabular}{|c|c|c|c|c|}
\hline \multirow{2}{*}{$\begin{array}{c}\text { Calculation } \\
\text { Method }\end{array}$} & \multicolumn{4}{|c|}{ Conformers } \\
\hline & $S_{I}^{*}$ & $\mathrm{~S}_{\mathrm{IV}}$ & $\mathbf{T}_{\mathrm{II}}$ & $S_{v}$ \\
\hline $\mathrm{HF} / 6-31 \mathrm{G}(\mathrm{d})$ & 6.56 & 9.77 & 32.81 & 0 \\
\hline $\mathrm{HF} / 6-31 \mathrm{G}(\mathrm{d}, \mathrm{p})$ & 6.44 & 9.80 & 32.79 & 0 \\
\hline MP2/6-31G(d,p) & 4.76 & 8.54 & 65.75 & 0 \\
\hline B3LYP/6-31G(d,p) & 2.53 & 8.64 & 53.66 & 0 \\
\hline BLYP/6-31G(d,p) & 5.37 & 8.92 & 42.18 & 0 \\
\hline BLYP/STO-6G & -0.80 & 5.68 & 28.45 & 0 \\
\hline
\end{tabular}

* No hindered rotor approximation analysis: 6-31G(d), 6-31G(d,p).

The $\Delta \mathrm{H}^{\circ}$ difference between $\mathrm{S}_{\mathrm{I}}$ and $\mathrm{T}_{\mathrm{II}}$ is a measure of the activation energy of the cis $\rightarrow$ trans reaction in a non-adiabatic process. The lower value for this difference is obtained with $\mathrm{HF}$ method $\left(\approx+26 \mathrm{kcal} \mathrm{mol}^{-1}\right)$; BLYP/STO$6 \mathrm{G}$ yields a value of $\approx+29 \mathrm{kcal} \mathrm{mol}^{-1}$, while BLYP/6-31G(d,p), B3LYP/6- 
$31 \mathrm{G}(\mathrm{d}, \mathrm{p})$ and MP2/6-31G(d,p) overestimate this difference $(\approx+37,+51$ and $\left.+61 \mathrm{kcal} \mathrm{mol}^{-1}\right)$. The BLYP/STO-6G value agrees with the expected results, which are found to be $\approx+25 \mathrm{kcal} \mathrm{mol}^{-1} .{ }^{11}$

The $\Delta \mathrm{H}^{\circ}$ difference between $\mathrm{S}_{\mathrm{I}}$ and $\mathrm{S}_{\mathrm{IV}}\left(\mathrm{S}_{\mathrm{I}} \rightarrow \mathrm{S}_{\mathrm{IV}}\right)$ is underestimated by $\mathrm{HF}$ method $\left(\approx+3.3 \mathrm{kcal} \mathrm{mol}^{-1}\right)$, BLYP/6-31G $(\mathrm{d}, \mathrm{p})\left(\approx+3.6 \mathrm{kcal} \mathrm{mol}^{-1}\right)$ and MP2 $/ 6$ $31 \mathrm{G}(\mathrm{d}, \mathrm{p})\left(\approx+3.8 \mathrm{kcal} \mathrm{mol}^{-1}\right)$. B3LYP/6-31G(d,p) yields a value of $\approx+6.1 \mathrm{kcal}$ $\mathrm{mol}^{-1}$, while with BLYP/STO-6G the $\Delta \mathrm{H}^{\circ}$ difference is of $\approx+6.5 \mathrm{kcal} \mathrm{mol}$ ${ }^{1}$, a reasonable value for a strong intramolecular hydrogen bond. ${ }^{17}$ Thus, the stabilization energy of the hydrogen bond allows maleic acid being as stable as fumaric acid in gas phase.
If we compare the structural parameters of chosen conformers obtained with different approaches (see Table 2), one arrives to the conclusion that the hydrogen bond in $\mathrm{S}_{\mathrm{I}}$ conformer, and the triplet state is better modeled by using BLYP/STO-6G. For example, in regard to the hydrogen bond, the $\mathrm{O}_{9}-\mathrm{O}_{12}$ and $\mathrm{O}_{12}-\mathrm{H}_{10}$ distances are smaller, the $\mathrm{O}_{9}-\mathrm{H}_{10}$ bond length is larger, and the $\mathrm{O}_{9}-\mathrm{H}_{1}-\mathrm{O}_{1}$ angle is closer to $180^{\circ}$; in relation to the triplet state, $\mathrm{C}_{1}=\mathrm{C}_{3}$ bond length is larger, so the spin-spin repulsion is decreased. On the other hand, the intrinsic repulsion between $\mathrm{O}(9)$ and $\mathrm{O}(12)$ in $\mathrm{S}_{\mathrm{IV}}$ is minimized as a result of the BLYP/STO-6G calculation and thus, the $\mathrm{O}_{9}-\mathrm{O}_{12}$ distance is smaller. Maleic acid have planar ring structure in the crystalline state, with $\mathrm{O}_{9}-\mathrm{O}_{12}$ distance $(246$ $\mathrm{pm}$ ) which indicates strong hydrogen bond. ${ }^{18,19}$ The planar structure of $\mathrm{S}_{\mathrm{I}}, \mathrm{S}_{\mathrm{IV}}$ and $\mathrm{S}_{\mathrm{V}}$ forms and the right $\Phi_{1}$ dihedral angle in $\mathrm{T}_{\mathrm{II}}$ is obtained by the various calculation methods.

Table 2. Geometrical parameters of relevant conformers obtained by several methods.

\begin{tabular}{|c|c|c|c|c|c|c|c|c|}
\hline \multirow{2}{*}{$\begin{array}{l}\text { Geometrical } \\
\text { Parameters }\end{array}$} & \multicolumn{4}{|c|}{ HF/6-31G(d) } & \multicolumn{4}{|c|}{ HF/6-31G(d,p) } \\
\hline & $\mathbf{S}_{\mathrm{I}}$ & $\mathrm{S}_{\mathrm{IV}}$ & $\mathbf{T}_{\mathrm{II}}$ & $\mathbf{S}_{\mathrm{v}}$ & $S_{I}$ & $\mathrm{~S}_{\mathrm{IV}}$ & $T_{I I}$ & $S_{v}$ \\
\hline \multicolumn{9}{|c|}{ Bond/pm } \\
\hline $\mathrm{C}_{1}=\mathrm{C}_{3}$ & 132.7 & 132.5 & 147.0 & 131.9 & 132.6 & 132.4 & 147.0 & 131.9 \\
\hline $\mathrm{C}_{5}-\mathrm{O}_{12}$ & 119.7 & 118.3 & 119.4 & 118.8 & 119.8 & 118.3 & 119.5 & 118.8 \\
\hline $\mathrm{C}_{6}-\mathrm{O}_{9}$ & 130.9 & 131.4 & 133.2 & 132.6 & 130.8 & 131.3 & 133.0 & 132.5 \\
\hline $\mathrm{O}_{9}-\mathrm{H}_{10}$ & 95.8 & 95.2 & 95.2 & 95.2 & 95.5 & 94.8 & 94.8 & 94.8 \\
\hline $\mathrm{O}_{12}-\mathrm{H}_{10}$ & 174.4 & & & & 173.2 & & & \\
\hline $\mathrm{O}_{9}-\mathrm{O}_{12}$ & 268.0 & 273.9 & & & 266.5 & 274.0 & & \\
\hline \multicolumn{9}{|c|}{ Angle/deg } \\
\hline $\mathrm{C}_{1}-\mathrm{C}_{5}=\mathrm{O}_{12}$ & 126.9 & 129.0 & 123.5 & 125.3 & 126.8 & 128.9 & 123.4 & 125.2 \\
\hline $\mathrm{C}_{3}-\mathrm{C}_{6}-\mathrm{O}_{9}$ & 121.0 & 117.2 & 112.7 & 111.5 & 120.9 & 117.2 & 112.8 & 111.6 \\
\hline $\mathrm{C}_{6}-\mathrm{O}_{9}-\mathrm{H}_{10}$ & 113.9 & 108.0 & 108.2 & 108.5 & 114.0 & 108.2 & 108.4 & 108.7 \\
\hline $\mathrm{C}_{5}=\mathrm{O}_{12}-\mathrm{H}_{10}$ & 110.7 & & & & 110.8 & & & \\
\hline $\mathrm{O}_{9}-\mathrm{H}_{10}-\mathrm{O}_{12}$ & 164.5 & & & & 164.7 & & & \\
\hline \multicolumn{9}{|c|}{ Dihedral/deg } \\
\hline$\Phi_{1}$ & 0 & 0 & 88.8 & 180 & 0 & 0 & 88.8 & 180 \\
\hline$\Phi_{2}$ & 180 & 180 & 0.7 & 180 & 180 & 180 & 0.6 & 180 \\
\hline$\Phi_{3}$ & 0 & 0 & -179.7 & 180 & 0 & 0 & -179.8 & 180 \\
\hline $12=5-7-8$ & 0 & 0 & 1.4 & 0 & 0 & 0 & 1.4 & 0 \\
\hline $10-9-6=11$ & 180 & 0 & -0.5 & 0 & 180 & 0 & -0.5 & 0 \\
\hline
\end{tabular}

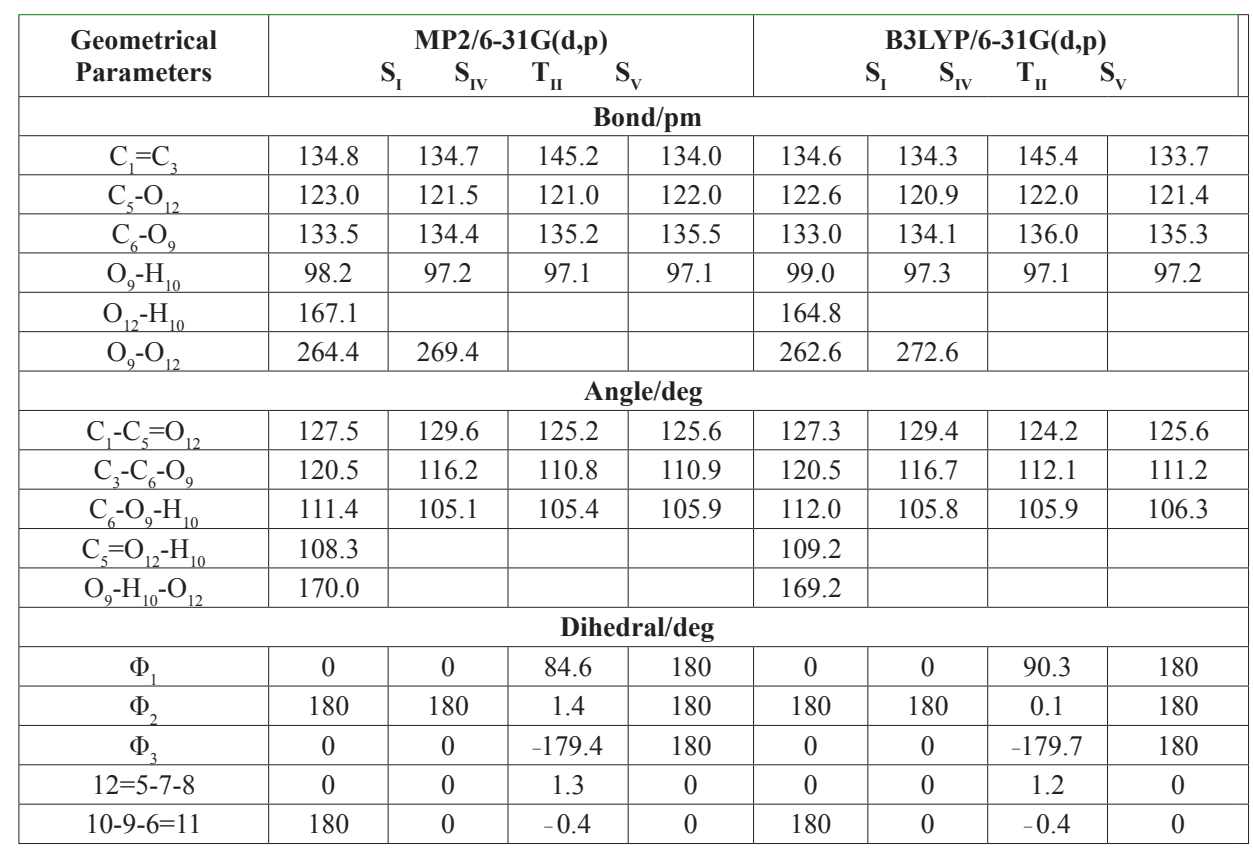




\begin{tabular}{|c|c|c|c|c|c|c|c|c|}
\hline \multirow{2}{*}{$\begin{array}{l}\text { Geometrical } \\
\text { Parameters }\end{array}$} & \multicolumn{4}{|c|}{ BLYP/6-31G(d,p) } & \multicolumn{4}{|c|}{ BLYP/STO-6G } \\
\hline & \multicolumn{2}{|c|}{$S_{I} \quad S_{I V}$} & \multicolumn{2}{|c|}{$\Gamma_{\text {II }} \quad S_{V}$} & & \multirow[t]{2}{*}{$S_{I} \quad S_{I V}$} & \multirow[t]{2}{*}{$T_{\text {II }}$} & \\
\hline \multicolumn{5}{|c|}{ Bond/pm } & & & & \\
\hline $\mathrm{C}_{1}=\mathrm{C}_{3}$ & 133.8 & 133.6 & 147.0 & 133.0 & 134.0 & 133.8 & 150.3 & 133.5 \\
\hline $\mathrm{C}_{5}-\mathrm{O}_{12}$ & 121.2 & 119.7 & 120.8 & 120.2 & 125.3 & 123.6 & 129.6 & 123.9 \\
\hline $\mathrm{C}_{6}-\mathrm{O}_{9}$ & 132.4 & 133.1 & 134.8 & 134.3 & 137.8 & 140.2 & 141.5 & 140.7 \\
\hline $\mathrm{O}_{9}-\mathrm{H}_{10}$ & 96.9 & 96.0 & 96.0 & 96.0 & 102.5 & 100.9 & 100.8 & 100.9 \\
\hline $\mathrm{O}_{12}-\mathrm{H}_{10}$ & 172.6 & & & & 149.5 & & & \\
\hline $\mathrm{O}_{9}-\mathrm{O}_{12}$ & 267.7 & 276.0 & & & 251.9 & 259.1 & & \\
\hline \multicolumn{9}{|c|}{ Angle/deg } \\
\hline $\mathrm{C}_{1}-\mathrm{C}_{5}=\mathrm{O}_{12}$ & 127.1 & 129.1 & 123.7 & 125.5 & 127.4 & 130.5 & 124.5 & 126.7 \\
\hline $\mathrm{C}_{3}-\mathrm{C}_{6}-\mathrm{O}_{9}$ & 120.8 & 117.0 & 112.4 & 111.3 & 120.7 & 115.1 & 115.0 & 111.0 \\
\hline $\mathrm{C}_{6}-\mathrm{O}_{9}-\mathrm{H}_{10}$ & 113.0 & 107.2 & 107.4 & 107.6 & 108.4 & 102.6 & 102.5 & 103.1 \\
\hline $\mathrm{C}_{5}=\mathrm{O}_{12}-\mathrm{H}_{10}$ & 110.0 & & & & 109.1 & & & \\
\hline $\mathrm{O}_{9}-\mathrm{H}_{10}-\mathrm{O}_{12}$ & 166.4 & & & & 176.1 & & & \\
\hline \multicolumn{9}{|c|}{ Dihedral/deg } \\
\hline$\Phi_{1}$ & 0 & 0 & 89.9 & 180 & 0 & 0 & 90.1 & 180 \\
\hline$\Phi_{2}$ & 180 & 180 & 0.3 & 180 & 180 & 180 & -0.3 & 180 \\
\hline$\Phi_{3}$ & 0 & 0 & -179.8 & 180 & 0 & 0 & 179.8 & 180 \\
\hline $12=5-7-8$ & 0 & 0 & 1.3 & 0 & 0 & 0 & 0.5 & 0 \\
\hline $10-9-6=11$ & 180 & 0 & -0.5 & 0 & 180 & 0 & -0.6 & 0 \\
\hline
\end{tabular}

Trends in the electronic charge distributions may provide some additional insight into the intramolecular hydrogen bond. Table 3 displays the computed Mulliken charge ${ }^{20,21}$ of the atoms involved in the hydrogen bond interaction, i.e. $\mathrm{H}(10), \mathrm{O}(9)$ and $\mathrm{O}(12)$. Substantial change are observed in going from $\mathrm{HF} / 6-$ $31 \mathrm{G}(\mathrm{d})$ to BLYP/STO-6G, where the absolute values of the charges diminishes. Thus, the electrostatic interaction between the two oxygens is expected to be less repulsive with BLYP/STO-6G. Besides, the decreasing of the charge points up the covalent character of the intramolecular hydrogen bond, which is indicative of its strong nature.

Table 3. Mulliken charges of $S_{I}$ calculated at different levels of theory.

\begin{tabular}{|c|c|c|c|c|c|c|}
\hline & HF & HF & MP2 & B3LYP & BLYP & BLYP \\
Atom & $\mathbf{6 - 3 1 G ( d )}$ & $\mathbf{6 - 3 1 G ( d , p )}$ & $\mathbf{6 - 3 1 G ( d , p )}$ & $\mathbf{6 - 3 1 G ( d , p )}$ & $\mathbf{6 - 3 1 G ( d , p )}$ & STO-6G \\
\hline $\mathrm{H}(10)$ & 0.540 & 0.421 & 0.440 & 0.365 & 0.388 & 0.246 \\
\hline $\mathrm{O}(9)$ & -0.739 & -0.630 & -0.654 & -0.512 & -0.573 & -0.311 \\
\hline $\mathrm{O}(12)$ & -0.618 & -0.624 & -0.647 & -0.513 & -0.569 & -0.256 \\
\hline
\end{tabular}

In summary, it is shown that the BLYP/STO-6G level of theory is the most reliable in this study since this theoretical description reproduce reasonably well the experimental results. In consequence, the BLYP/STO-6G PES were calculated for both singlet and triplet electronic states of the molecule, with the purpose to show that the cis $\rightarrow$ trans isomerization evolves through a nonadiabatic path.

The BLYP/STO-6G PES of 2-butenedioic acid is shown in Figure 4 for the singlet (S-PES) and triplet (T-PES) electronic states. Qualitatively, both surfaces show distinctive features. For example, at S-PES large variations in energy take place through the $\Phi_{1}$ dihedral angle, irrespectively of $\Phi_{2}$, while the opposite in regard to the angles is generally true at T-PES (except for $\left[\Phi_{1}\right.$, $\left.\left.\Phi_{2}\right]=\left[180^{\circ}, 180^{\circ}\right]\right)$. Briefly, these facts could be explained as follows: we shall assume, for simplicity, that the state of the molecule can be represented by the two electrons forming the $\mathrm{p}$ system. At the singlet state, when $\Phi_{1}=$ $0^{\circ}$ or $180^{\circ}$ maximum overlap of the two p-orbitals occurs and spin pairing of the $\mathrm{p}$ electrons has its lowest energy, so that a pair of electrons occupy a bonding molecular orbital. If $\Phi_{1}=90^{\circ}$, the overlap is not possible, and the two electrons will occupy a non-bonding orbital. At the triplet state, with $\Phi_{1}$ $=0^{\circ}$ the electrons occupy different orbitals, one of them a bonding molecular orbital the other an antibonding molecular orbital. If $\Phi_{1}=90^{\circ}$, both electrons will occupy non-bonding orbitals and so, low energy differences are found with respect to the situation at which $\Phi_{1}=0^{\circ}$. Therefore, since these dihedral angles denote extreme conditions, the energy should not vary notoriously with $\Phi_{1}$.

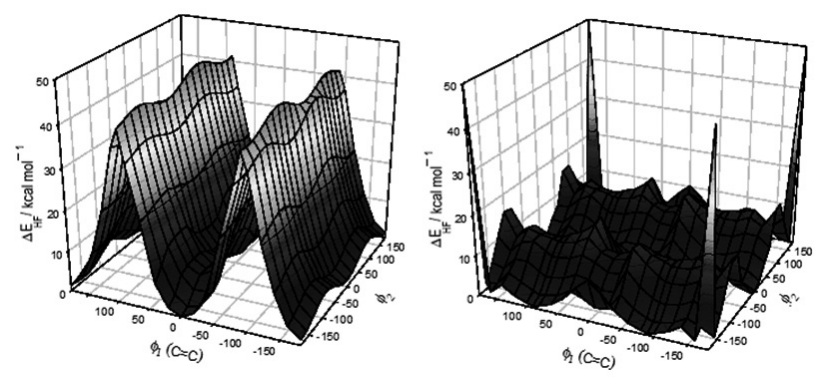

Figure 4. PES of 2-butenedioic acid. S-PES: [RBLYP/STO-6G] (left) and T-PES: [UBLYP/STO-6G] (right). $\Delta \mathrm{E}_{\mathrm{HF}}$ in $\mathrm{kcal} \mathrm{mol}^{-1}$ with respect to the global minimum of each PES.

The global minimum at the S-PES are located in $\left[\Phi_{1}, \Phi_{2}\right]=\left[0^{\circ}, 180^{\circ}\right]$, for T-PES at $\left[\Phi_{1}, \Phi_{2}\right]=\left[180^{\circ}, 0^{\circ}\right]$. There is a correspondence between the symmetry of the PES and the symmetry of the molecule.

The energy barriers for the interconversion between maleic acid and fumaric acid following an adiabatic path can be observed in the S-PES (see Figure 4 , left). In order to obtain information about possible reaction paths through a non-adiabatic process, we superimpose both potential energy surfaces and find another combined PES containing the lowest value of the energy for each pair of dihedral angles (see Figure 5). Thus, reaction mechanisms can be found starting from a singlet state, going through a triplet state and ending in a singlet state, following the lowest energy paths. 

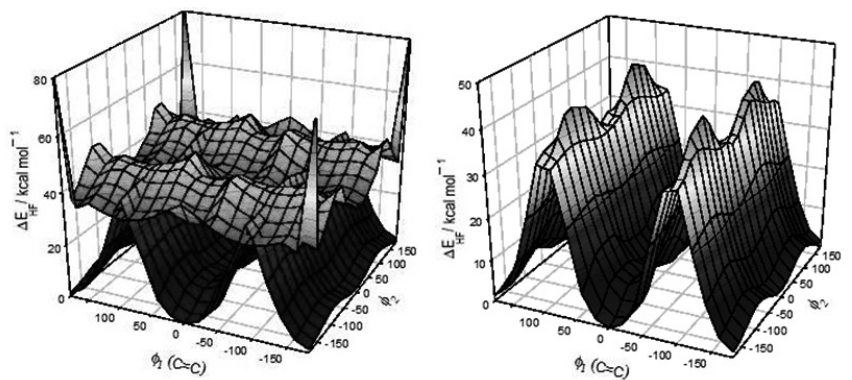

Figure 5. Superposition PES (left) and ST-PES (right) of 2-butenedioic acid. BLYP/STO-6G $\Delta \mathrm{E}_{\mathrm{HF}}$ in $\mathrm{kcal} \mathrm{mol}^{-1}$ with respect to the global minimum of S-PES.

Some important conformers obtained of the BLYP/STO-6G PES were submitted to a thermochemical analysis (298.15 K and $1 \mathrm{~atm})$. BLYP/STO-6G results of these and of the previously studied structures, are shown in Table 4 and can be compared to the obtained with different levels of theory. The set of conformers $\mathrm{S}_{\mathrm{I}}-\mathrm{S}_{\mathrm{IV}}$ correspond to the maleic acid, while $\mathrm{S}_{\mathrm{V}}$ and $\mathrm{S}_{\mathrm{VI}}$ correspond to fumaric acid. $\mathrm{S}_{\mathrm{IU}}:\left[+2.0^{\circ},+26.0^{\circ}\right]$ and $\mathrm{S}_{\mathrm{IWb}}:\left[-2.0^{\circ},-26.0^{\circ}\right]$ constitute a pair of mirror images or enantiomers (the same can be said for $\mathrm{S}_{\mathrm{IJ}} / \mathrm{S}_{\mathrm{IJ}}, \mathrm{T}_{\mathrm{I}} / \mathrm{T}_{\mathrm{Ib}}$, $\left.\mathrm{T}_{\mathrm{III}} / \mathrm{T}_{\mathrm{III}}, \mathrm{S}_{\mathrm{VIII}} / \mathrm{S}_{\mathrm{VII}}, \mathrm{S}_{\mathrm{VIII}} / \mathrm{S}_{\mathrm{VIII}}\right)$. The $\mathrm{S}_{\mathrm{III}}$ conformers could only be calculated at BLYP/STO-6G level and resembles to $\mathrm{S}_{1}$ in the sense that also display an intramolecular hidrogen bond $\left(\Phi_{3} \approx 7^{\circ}, \mathrm{O}_{9}-\mathrm{H}_{10}-\mathrm{O}_{7} \approx 173^{\circ}, \mathrm{O}_{9}-\mathrm{O}_{7} \approx 253 \mathrm{pm}\right)$. $\mathrm{T}_{1}$ and $\mathrm{T}_{\text {II }}$ represent minima on the T-PES, and become saddle points in the STPES, clearly identified as hypothetical "activated complexes".

In general, by using large basis set, Hartree-Fock method overestimate the enthalpy difference between the maleic and fumaric acid, while MP2 and B3LYP overestimate the enthalpy difference between the triplet state and the most stable cis conformer.

Table 4. Dihedral angles ${ }^{\mathrm{a}}$, relative electronic energy $\left(\Delta \mathrm{E}_{\mathrm{HF}}, \Delta \mathrm{E}_{\mathrm{B} 3 \mathrm{LY}}, \Delta \mathrm{E}_{\mathrm{BLYP}}\right), \Delta \mathrm{G}^{\circ}, \Delta \mathrm{H}^{\circ}$ and $\Delta \mathrm{S}^{\circ}$ of the 2-butenedioic acid conformers $(\mathrm{C})$ obtained using different methods. Relative energies ${ }^{\mathrm{b}}$ and entropies ${ }^{\mathrm{c}}$ are reported with respect to the $\mathrm{S}_{\mathrm{V}}$ conformer.

\begin{tabular}{|c|c|c|c|c|c|c|c|c|c|c|c|c|}
\hline \multirow{2}{*}{$\mathbf{C}$} & \multicolumn{6}{|c|}{ BLYP/STO-6G } & \multicolumn{6}{|c|}{ BLYP/6-31G(d,p) } \\
\hline & $\Phi_{1}$ & $\Phi_{2}$ & $\Delta \mathbf{E}_{\text {BLYP }}$ & $\Delta \mathbf{G}^{\circ}$ & $\Delta \mathbf{H}^{\circ}$ & $\Delta \mathbf{S}^{\circ}$ & $\Phi_{\mathrm{I}}$ & $\Phi_{2}$ & $\Delta \mathbf{E}_{\text {B3LYP }}$ & $\Delta \mathbf{G}^{\circ}$ & $\Delta \mathbf{H}^{\circ}$ & $\Delta \mathbf{S}^{\circ}$ \\
\hline $\mathrm{S}_{\mathrm{I}}^{*}$ & 0 & 180 & -1.34 & 0.31 & -0.80 & $-3,71$ & 0 & 180 & 5.38 & 5.62 & 5.37 & -0.84 \\
\hline $\mathrm{S}_{\mathrm{II}}$ & \pm 1.2 & \pm 65.5 & 4.34 & 3.52 & 4.32 & 2.69 & \pm 0.6 & 干75.9 & 6.70 & 5.92 & 6.48 & 1.88 \\
\hline $\mathrm{S}_{\mathrm{III}}^{*}$ & \pm 2.0 & \pm 26.0 & 2.55 & 3.84 & 3.09 & -2.51 & & & & & & \\
\hline $\mathrm{S}_{\mathrm{IV}}$ & 0 & 180 & 6.19 & 6.41 & 5.68 & -2.44 & 0 & 180 & 10.16 & 11.43 & 8.92 & -8.42 \\
\hline $\mathrm{T}_{\mathrm{I}}$ & \pm 89.8 & \pm 179.2 & 33.01 & 27.74 & 28.72 & 3.29 & \pm 90.8 & $\mp 179.0$ & 44.49 & 40.93 & 42.06 & 3.82 \\
\hline $\mathrm{T}_{\text {II }}$ & \pm 90.1 & $\mp 0.3$ & 32.68 & 27.10 & 28.45 & 4.54 & \pm 89.9 & \pm 0.3 & 44.60 & 40.67 & 42.18 & 5.08 \\
\hline $\mathrm{S}_{\mathrm{v}}$ & 180 & 180 & 0 & 0 & 0 & 0 & 180 & 180 & 0 & 0 & 0 & 0 \\
\hline $\mathrm{S}_{\mathrm{VI}}$ & 180 & 0 & 0.35 & -0.04 & 0.38 & 1.40 & 180 & 0 & 0.56 & 0.09 & 0.54 & 1.50 \\
\hline $\mathrm{S}_{\mathrm{VII}}$ & \pm 90.0 & \pm 38.3 & 39.59 & 38.63 & 38.83 & 0.69 & \pm 90.0 & 干38.8 & 38.40 & 38.07 & 37.35 & -2.40 \\
\hline $\mathrm{S}_{\mathrm{VIII}}$ & \pm 90.0 & 干158.3 & 40.08 & 39.53 & 39.30 & -0.79 & \pm 90.0 & \pm 169.9 & 40.31 & 39.73 & 39.23 & -1.69 \\
\hline
\end{tabular}

\begin{tabular}{|c|c|c|c|c|c|c|c|c|c|c|c|c|}
\hline \multirow{2}{*}{ C } & \multicolumn{6}{|c|}{ MP2/6-31G(d,p) } & \multicolumn{6}{|c|}{ B3LYP/6-31G(d,p) } \\
\hline & $\Phi_{I}$ & $\Phi_{2}$ & $\Delta \mathbf{E}_{\text {BLYP }}$ & & $\Delta \mathbf{H}^{\circ}$ & $\Delta \mathrm{S}^{\circ}$ & $\Phi_{I}$ & $\Phi_{2}$ & $\Delta \mathbf{E}_{\text {B3LYP }}$ & & $\Delta \mathbf{H}^{\circ}$ & $\Delta \mathbf{S}^{\circ}$ \\
\hline $\mathrm{S}_{\mathrm{I}}^{*}$ & 0 & 180 & 4.83 & 5.06 & 4.76 & -0.99 & 0 & 180 & 2.66 & -2.20 & 2.53 & 15.86 \\
\hline $\mathrm{S}_{\mathrm{II}}$ & \pm 1.5 & $\mp 80.7$ & 5.62 & 4.96 & 5.39 & 1.45 & \pm 1.2 & 干74.8 & 6.58 & 0.68 & 6.38 & 19.11 \\
\hline \multicolumn{13}{|l|}{$\mathrm{S}_{\mathrm{III}}$} \\
\hline $\mathrm{S}_{\mathrm{IV}}$ & 0 & 180 & 9.88 & 11.16 & 8.54 & -8.76 & 0 & 180 & 9.24 & 3.81 & 8.64 & 16.20 \\
\hline $\mathrm{T}_{\mathrm{I}}$ & \pm 84.4 & $\mp 177.6$ & 66.49 & 64.34 & 65.52 & 3.93 & \pm 91.6 & $\mp 179.2$ & 56.24 & 47.66 & 54.02 & 21.33 \\
\hline $\mathrm{T}_{\text {II }}$ & \pm 84.6 & \pm 1.4 & 66.69 & 64.19 & 65.75 & 5.24 & \pm 90.3 & 0.0 & 55.85 & 46.96 & 53.66 & 22.47 \\
\hline $\mathrm{S}_{\mathrm{v}}$ & 180 & 180 & 0 & 0 & 0 & 0 & 180 & 180 & 0 & 0 & 0 & 0 \\
\hline $\mathrm{S}_{\mathrm{VI}}{ }^{*}$ & 180 & 0 & 0.62 & 0.18 & 0.50 & 1.10 & 180 & 0 & 0.60 & -4.98 & 0.59 & 18.69 \\
\hline $\mathrm{S}_{\mathrm{VII}}$ & \pm 90.0 & $\mp 41.7$ & 36.29 & 36.08 & 35.29 & -2.64 & \pm 90.0 & \pm 41.0 & 35.19 & 29.66 & 34.15 & 15.06 \\
\hline $\mathrm{S}_{\mathrm{VIII}}$ & \pm 90.0 & \pm 165.9 & 38.30 & 37.44 & 37.30 & -0.45 & \pm 90.0 & $\mp 170.0$ & 37.19 & 31.01 & 36.10 & 17.07 \\
\hline
\end{tabular}




\begin{tabular}{|c|c|c|c|c|c|c|c|c|c|c|c|c|}
\hline \multirow{2}{*}{$\mathrm{C}$} & \multicolumn{6}{|c|}{ HF/6-31G(d) } & \multicolumn{6}{|c|}{ HF/6-31G(d,p) } \\
\hline & $\Phi_{I}$ & $\Phi_{2}$ & $\Delta \mathbf{E}_{\mathrm{HF}}$ & $\Delta \mathbf{G}^{\circ}$ & $\Delta \mathbf{H}^{\circ}$ & $\Delta \mathbf{S}^{\circ}$ & $\Phi_{\mathrm{I}}$ & $\Phi_{2}$ & $\Delta \mathbf{E}_{\mathrm{HF}}$ & $\Delta \mathbf{G}^{\circ}$ & $\Delta \mathbf{H}^{\circ}$ & $\Delta \mathbf{S}^{\circ}$ \\
\hline $\mathrm{S}_{\mathrm{I}}^{*}$ & 0 & 180 & 6.48 & 6.74 & 6.56 & -0.60 & 0 & 180 & 6.40 & 6.64 & 6.44 & -0.67 \\
\hline $\mathrm{S}_{\mathrm{II}}$ & \pm 0.6 & $\mp 78.8$ & 6.69 & 6.02 & 6.46 & 1.48 & \pm 0.6 & 干78.8 & 6.65 & 6.00 & 6.43 & 1.44 \\
\hline \multicolumn{13}{|l|}{$\mathrm{S}_{\mathrm{III}}$} \\
\hline $\mathrm{S}_{\mathrm{IV}}$ & 0 & 180 & 10.98 & 12.28 & 9.77 & -8.42 & 0 & 180 & 11.01 & 12.31 & 9.80 & -8.42 \\
\hline $\mathrm{T}_{\mathrm{I}}$ & \pm 89.6 & $\mp 178.7$ & 35.27 & 31.41 & 32.53 & 3.76 & \pm 89.6 & 干178.7 & 35.23 & 31.41 & 32.51 & 3.69 \\
\hline $\mathrm{T}_{\mathrm{II}}$ & \pm 88.8 & \pm 0.7 & 35.57 & 31.31 & 32.81 & 5.03 & \pm 88.8 & \pm 0.6 & 35.55 & 31.30 & 32.79 & 5.00 \\
\hline $\mathrm{S}_{\mathrm{v}}$ & 180 & 180 & 0 & 0 & 0 & 0 & 180 & 180 & 0 & 0 & 0 & 0 \\
\hline $\mathrm{S}_{\mathrm{VI}}{ }^{*}$ & 180 & 0 & 0.50 & 0.132 & 0.40 & 0.90 & 180 & 0 & 0.50 & 0.134 & 0.40 & 0.88 \\
\hline $\mathrm{S}_{\mathrm{VII}}$ & \pm 90.0 & \pm 37.6 & 42.16 & 41.88 & 41.13 & -2.52 & \pm 90.0 & \pm 37.5 & 42.15 & 41.86 & 41.11 & -2.52 \\
\hline $\mathrm{S}_{\mathrm{VIII}}$ & \pm 90.0 & 干169.6 & 44.17 & 43.24 & 43.12 & -0.40 & \pm 90.0 & $\mp 170.4$ & 44.16 & 43.21 & 43.09 & -0.40 \\
\hline
\end{tabular}

Units: ${ }^{\mathrm{a}}$ degrees; ${ }^{\mathrm{b}} \mathrm{kcal} \mathrm{mol}{ }^{-1} ;{ }^{\mathrm{c}} \mathrm{cal} \mathrm{K} \mathrm{K}^{-1} \mathrm{~mol}^{-1}$.

${ }^{*}$ No hindered rotor approximation analysis: $\mathrm{S}_{\mathrm{I}}(6-31 \mathrm{G}(\mathrm{d}), 6-31 \mathrm{G}(\mathrm{d}, \mathrm{p})), \mathrm{S}_{\mathrm{III}}$ and $\mathrm{S}_{\mathrm{VI}}(\mathrm{HF}, \mathrm{MP} 2)$.

Notoriously, the standard B3LYP/6-31G(d,p) procedure is not appropriate for the study of the isomerization process. For instance, the enthalpy change of $\mathrm{S}_{\mathrm{I}} \rightarrow \mathrm{S}_{\mathrm{V}}$ reaction is $-2.53 \mathrm{kcal} \mathrm{mol}^{-1}$, which is in clear contradiction with the experimental result of $+0.86 \mathrm{kcal} \mathrm{mol}^{-1}$; the entropy change is negative and it is overestimated for the isomerization reaction. As a consequence, $\mathrm{S}_{\mathrm{I}}$ appears as more stable than $\mathrm{S}_{\mathrm{V}}$, because the $\Delta \mathrm{G}^{\circ}$ for $\mathrm{S}_{\mathrm{I}} \rightarrow \mathrm{S}_{\mathrm{V}}$ reaction is $2.20 \mathrm{kcal} \mathrm{mol}^{-}$ ${ }^{1}$. In addition, $\mathrm{S}_{\mathrm{I}}$ and $\mathrm{S}_{\mathrm{VI}}$ are very similar structures and therefore, the large difference in $\Delta \mathrm{G}^{\circ}$ values is not justified. In other respects, in virtue of the difference in activation enthalpy between triplet and singlet states, the adiabatic mechanism would be more probable than the non-adiabatic path.

It can be said that isomerization energies closer to experimental are found with BLYP/STO-6G level. The principal driving force for $\mathrm{S}_{\mathrm{L}} \rightarrow \mathrm{S}_{\mathrm{v}}$ isomerization reaction is of entropic nature, and as a consequence of the $\Delta \mathrm{G}^{\circ}$ values, both trans conformers are equally stable. The $\mathrm{S}_{\mathrm{IV}}$ conformer (saddle point at BLYP/ STO-6G) is not stabilized by hydrogen bonding and there should also be more repulsion between the lone pair electrons of the two oxygens than in $\mathrm{S}_{\mathrm{f}}$. These two effects are expected to result in a fairly high energy for the $\mathrm{S}_{\mathrm{IV}}$ in agreement with the present calculations. As the BLYP/STO- $6 \mathrm{G} \Delta \mathrm{G}^{\circ}$ of $\mathrm{T}_{\mathrm{I}}$ and $\mathrm{T}_{\mathrm{II}}$ is lower than the energy barrier in the S-PES (depicted by $\mathrm{S}_{\mathrm{VII}}$ and $\mathrm{S}_{\mathrm{VIII}}$ ) we can conclude that the non-adiabatic mechanism is more probable than the adiabatic path.

Finally, conformational energy map based on ST-PES of 2-butenedioic acid is shown in Figure 6. In this contour diagram some of the possible reaction paths that interconnect cis and trans isomers are shown. The internal rotations through $\Phi_{2}\left(\Phi_{1} \approx 0^{\circ}\right)$ involves, respectively, energy barriers $<5 \mathrm{kcal} \mathrm{mol}^{-1}$ and $<2 \mathrm{kcal} \mathrm{mol}^{-1}$ for the $\mathrm{S}_{\mathrm{I}} \leftrightarrow \mathrm{S}_{\text {III }}$ and $\mathrm{S}_{\text {IIIa }} \leftrightarrow \mathrm{S}_{\text {IIIb }}$ interconversions; while through $\Phi_{2}\left(\Phi_{1}=180^{\circ}\right)$ the rotation barriers are of $\approx 5 \mathrm{kcal} \mathrm{mol}^{-1}$. Thus, in this context, conformational equilibria are possible at ambient temperature.

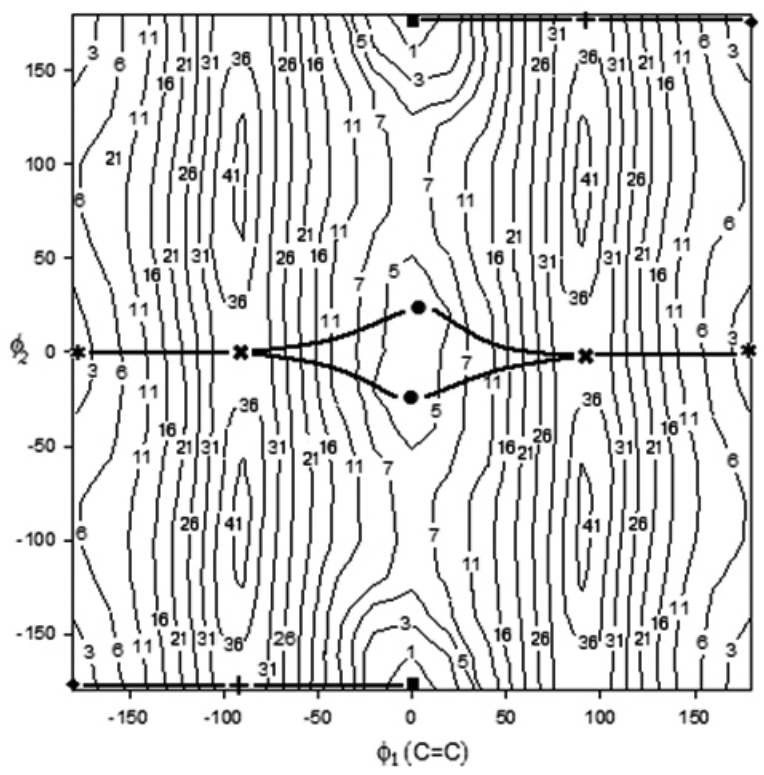

Figure 6. Conformational energy map. Position of stationary points and possible reaction path.

Notation: $\mathrm{S}_{\mathrm{I}}(\boldsymbol{\square}) ; \mathrm{S}_{\mathrm{III}}(\bullet) ; \mathrm{T}_{\mathrm{I}}(+) ; \mathrm{T}_{\mathrm{II}}(\mathrm{W}) ; \mathrm{S}_{\mathrm{V}}(\mathrm{g}) ; \mathrm{S}_{\mathrm{VI}}(\mathrm{r})$.

\section{CONCLUSIONS}

Experimental thermodynamic functions concerning isomerization of maleic acid to fumaric acid are well reproduced by theoretical calculation using a user-defined model at a BLYP / STO-6G level of theory. Stabilization of maleic acid by a strong hydrogen bond is well characterized with this method. Other methods, such as HF/6-31G(d,p), MP2/6-31G(d,p) and B3LYP/6$31 \mathrm{G}(\mathrm{d}, \mathrm{p})$ overestimate the enthalpy gap between maleic and fumaric acid, and qualitatively disagree with experiments in the sign of the enthalpy difference. The results of this study show the possibility that the cis $\rightarrow$ trans isomerization reaction in gas phase of the 2-butenedioic acid proceeds by a non-adiabatic path, with an enthalpy difference between the triplet state and the cis-planar most stable conformer of approximately $29 \mathrm{kcal} \mathrm{mol}^{-1}$. 


\section{ACKNOWLEDGEMENTS}

The authors wish to acknowledge the DID-UACH (Grant S-2008-26) and Fondecyt (Grant 1090341) for finantial support.

\section{REFERENCES}

1. E.M. Terry, L. Eichelberger, J. Am. Chem. Soc. 47, 1402, (1925)

2. C. Horrex, Trans. Faraday. Soc. 33, 570, (1937)

3. K. Nozaki, R. Ogg, J. Am. Chem. Soc. 63, 2583, (1941)

4. D.H. Derbyshire, W.A. Waters, Trans. Faraday Soc. 45, 749, (1949)

5. R. Kiyama, S. Minomura, The Review of Physical Chemistry of Japan. 22 , 4, (1954)

6. M. Davies, F.P. Evans, Trans. Faraday Soc. 52, 74, (1956)

7. S. Seltzer, J. Am. Chem. Soc. 83, 1861, (1961)

8. J.S Meek, J. Chem. Educ. 52, 541, (1975)

9. A.J. Castro, S.R. Ellenberger, J.P Sluka, J. Chem. Educ. 60, 521, (1983)

10. K. Hojendahl, J. Phys. Chem. 28, 758, (1924)

11. J.L. Magee, W. Shand Jr., H. Eyring, J. Am. Chem. Soc. 63, 677, (1941)

12. Gaussian 03, Revisión-B.03, M.J. Frisch, G.W. Trucks, H.B. Schlegel, G.E. Scuseria, M.A. Robb, J.R. Cheeseman, J.A. Montgomery, Jr., T. Vreven, K.N. Kudin, J.C. Burant, J.M. Millam, S.S. Iyengar, J. Tomasi, V. Barone, B. Mennucci, M. Cossi, G. Scalmani, N. Rega, G.A. Petersson, H. Nakatsuji, M. Hada, M. Ehara, K. Toyota, R. Fukuda, J. Hasegawa, M. Ishida, T. Nakajima, Y. Honda, O. Kitao, H. Nakai, M. Klene, X. Li, , J.E. Knox, H.P. Hratchian, J.B. Cross, C. Adamo, J. Jaramillo, R. Gomperts, R.E. Stratmann, O. Yazyev, A.J. Austin, R. Cammi, C. Pomelli, J.W. Ochterski, P.Y. Ayala, K. Morokuma, G.A. Voth, P. Salvador, J.J. Dannenberg, V.G. Zakrzewski, S. Dapprich, A.D. Daniels, M.C. Strain, O. Farkas, D.K. Malick, A.D. Rabuck, K. Raghavachari, J.B. Foresman,, J.V. Ortiz, Q. Cui, A.G. Baboul, S. Clifford, J. Cioslowski, B.B. Stefanov, G. Liu, A. Liashenko, P. Piskorz, I. Komaromi, R.L. Martin, D.J. Fox, T. Keith, M.A. Al-Laham, C.Y. Peng, A. Nanayakkara, M. Challacombe, P.M.W. Gill, B. Johnson, W. Chen, M.W. Wong, C. Gonzalez, J.A. Pople, Gaussian: Pittsburgh, PA, 2003.
13. E.M.S. Macoas, R. Fausto, J. Lundell, M. Pettersson, L. Khriachtchev, M. Räsänen, J. Phys. Chem. A. 105, 3922, (2001)

14. A.D. Becke, Phys. Rev. A. 38, 3098, (1988)

15. C. Lee, W. Yang, R.G. Parr, Phys. Rev. B. 37, 785, (1988)

16. David R. Lide, ed., CRC Handbook of Chemistry and Physics, 89th Edition (Internet Version 2009), CRC Press/Taylor and Francis, Boca Raton, FL.

17. P. Lipkowski, A. Koll, A. Karpfen, P. Wolschann, Chemical Physics Letters. 360, 256, (2002)

18. M. Shahat, Acta Cryst. 5, 763, (1952)

19. R.E. Dodd, R.E. Miller, W.F.K. Wynne-Jones, J. Chem. Soc. (Resumed), 2790, (1961)

20. R.S. Mulliken, J. Chem. Phys. 23, 1833, (1955)

21. J.S. Gómez-Jeria, J. Chil. Chem. Soc. 54, 482, (2009) 